DOI: http://dx.doi.org/10.18203/2349-2902.isj20182244

\title{
Retraction
}

The following article from International Surgery Journal 'Clinical study of right iliac fossa mass: experience at a rural hospital' (Int Surg J 2018;5:2311-5, DOI: http://dx.doi.org/10.18203/2349-2902.isj20182244), by Harshal B. Ramteke, Harmandeep Singh, Dhirendra D. Wagh, Rohini J. Bhoyar was published in the Volume 5, Issue 6, June 2018, has been retracted upon authors request. 


\title{
Original Research Article
}

\section{Clinical study of right iliac fossa mass: experience at a rural hospital}

\author{
Harshal B. Ramteke ${ }^{1 *}$, Harmandeep Singh ${ }^{1}$, Dhirendra D. Wagh ${ }^{1}$, Rohini J. Bhoyar ${ }^{2}$
}

\begin{abstract}
${ }^{1}$ Department of Surgery, Jawaharlal Nehru Medical College, Sawangi, Meghe, Wardha, Maharshtra, India
${ }^{2}$ Department of Gynaecology, NKP Salve Institute of Medical Sciences, Nagpur, Maharshtra, India
\end{abstract}

Received: 09 April 2018

Revised: 05 May 2018

Accepted: 08 May 2018

\section{*Correspondence:}

Dr. Harshal B. Ramteke,

E-mail: drharshalsurg@yahoo.com

Copyright: () the author(s), publisher and licensee Medip Academy. This is an open-access article distributed under the terms of the Creative Commons Attribution Non-Commercial License, which permits unrestricted non-commercial use, distribution, and reproduction in any medium, provided the original work is properly cited.

\section{ABSTRACT}

Background: Objectives of present study was to study the clinical profile, different modalities of investigation and various modes of management for Right Iliac Fossa (RIF) mass at a rural hospital, A.V.B.R.H.

Methods: Total 86 cases of RIF mass were studied prospectively for 4 years from August 2013 to September 2017. Patients above the age of 10 years presenting with a mass in RIF associated with acute/chronic abdominal conditions and incidentaly found mass in RIF on examination and investigation were included in the study. Patients with abdominal wall/bony swellings of the region and gynaecological causes of RIF mass were excluded. After detailed history and clinical examination, patients were subjected for different investigations to establish pathological diagnosis and treated accordingly.

Results: $69.76 \%$ cases with RIF mass were related to appendicular pathology. Of these $60.48 \%$ were appendicular mass and $9.3 \%$ were appendicular abscess. $13.95 \%$ cases were Carcinoma Caecum, 6.97\% cases were Ileo-caecal Tuberculosis, $6.97 \%$ were of ilio-psoas abscess and $2.32 \%$ cases were of Intusussception. Mean age of RIF mass was 37.41 years with a male preponderence of 1.4:1. Pain in abdomen was the commonest symptom. 16.28\%(14) cases were treated conservatively and $83.72 \%(72)$ were treated surgically.

Conclusions: Most common cause of RIF mass is appendicular lump (60.46\%) among various other pathologies. Pain in abdomen is the commonest presenting symptom. Interval appendectomy should be considered essential as the incidence of recurrence of appendicitis and mass formation is high after conservative treatment. Detailed history and thorough clinical examination is of utmost importance to reach the correct clinico-pathological diagnosis of RIF mass.

Keywords: Appendicular lump, Interval appendicectomy, Ileo-caecal tuberculosis, RIF mass

\section{INTRODUCTION}

A mass per abdomen has always been considered to be a temple wonders or Pandora's magic box. ${ }^{1}$ Despite the advancement in the field of diagnosis, the surprises never ceases, hence the abdomen has been rightly called temple of surprises. Mass in the right iliac fossa is one of the most common problems faced in surgical practice, which has various differential diagnosis. Most of the cases need surgical intervention and most of them are curable. The varied etiology of these conditions presents a diagnostic challenge to the surgeon, as appropriately said by Sir Hamilton Bailey "A correct diagnosis is the handmaiden of a successful operation". The mass in the right iliac fossa arises mainly from the appendix, caecum, terminal part of the ileum, lymph nodes, ileopsoas sheath and retroperitoneal connective tissue. An inflammatory mass in this region is most commonly associated with an appendicular pathology and rarely inflammatory swelling may arise in connection with suppurating iliac lymph nodes or a psoas abscess. The management of 
appendicular mass seems to take turn with the availability of better antibiotics, intensive care and anesthesia. ${ }^{2}$ When the surgeon encounters an unsuspected abscess during appendectomy it is usually best to proceed and remove the appendix. If the abscess is large and further dissection would be hazardous, drainage alone is appropriate. ${ }^{3}$ In India, tuberculosis has been reported to be the cause in 3 to $20 \%$ of patients with intestinal obstructions. ${ }^{4}$ Not infrequently a surgeon encounters a patient seeking consultation regarding the presence of a mass in the abdomen. Sometimes while examining the abdomen the clinician comes across a lump. The diagnosis of an abdominal mass requires skillful experience and mainly depends on clinical examination and investigations. Mass in the right iliac fossa is one of the most common problems faced in surgical practice, which has various differential diagnosis. Most of the cases need surgical intervention and most of them are curable. The purpose of this study was to know the incidence, various modes of presentation, different modalities of diagnosis, treatment and prognosis in our set up, studied to identify factors which can help in better management.

\section{METHODS}

This present study was done at Jawaharlal Nehru Medical College and AVBRH, Sawangi (M), Wardha, Maharashtra, over a period of 4 years between Aug 2013 to Sept 2017.A total of 86 cases of lump in right iliac fossa were studied prospectively. The study included all patients presenting with mass in right iliac fossa associated with acute or chronic abdominal conditions and masses which were found incidentally on examination and investigation. Patients having bony swellings of the region, children less than 10 years, gynecological causes of RIF mass and abdominal wall swellings were excluded from the study.

After obtaining a detailed history, patients were subjected to methodical physical examination and relevant findings were recorded. Rectal examination was done in all cases, per vaginal examination was also done in female patients. The essential investigations were done to establish the diagnosis. Treatment was planned according to the pathology in the form of either conservative or surgical management. Patients requiring surgical management were prepared adequately with bowel preparation, oral antibiotics and mechanical bowel cleansing whenever required. These cases were given postoperative parenteral antibiotics.

During laparotomy, intra-abdominal examination of all organs was made in addition to specific pathology. Relevant surgical procedures were done depending on the type of pathology. Most of the operated patients had uneventful recovery. Diagnosis of the pathology was confirmed by histopathology report. Patients were asked to present themselves for follow up during a specific interval or at recurrence of symptoms. Relevant data was collected in specifically designed case sheets.

\section{Statistical analysis}

Statistical analysis was done by using descriptive and inferential statistics using Chi-square test and software used in the analysis were SPSS 17.0 version and GraphPad Prism 5.0 version and $\mathrm{p}<0.05$ was considered as level of significance.

\section{RESULTS}

In present study, 86 cases of Right Iliac Fossa (RIF) Mass were chosen over a period of 4 years from August 2013 to September 2017. It was observed that the youngest patient was of age 10 years who presented with appendicular lump and the oldest was of 72 years of age admitted with carcinoma caecum and mean age of presentation of right iliac fossa mass was 37.41 years. More than half the cases of Appendicular lump manifested between2nddecadeand $3^{\text {rd }}$ decade $(57.7 \%)$ and the mean age was $30.88 \pm 17.30$ years. Appendicular abscess was common in $2^{\text {nd }}$ decade $(50 \%)$ followed by $4^{\text {th }}$ and $6^{\text {th }}$ decade $(25 \%)$ and mean age was $44.50 \pm 19.68$ years. Ileocaecal tuberculosis was common in the 5 thdecade $(66.66 \%)$ and mean age was $49 \pm 16.52$ years. Carcinoma caecum was common in the $3^{\text {rd }}$ and $6^{\text {th }}$ decade $(66.66 \%)$ and mean age was $57.16 \pm 16.77$ years. Ileopsoas abscess was distributed evenly in the $1^{\text {st }}, 3^{\text {rd }}$ and $4^{\text {th }}$ decade $(33.33 \%)$ each and mean age was $33.33 \pm 15.01$ years. Intussusception was found only in $3^{\text {rd }}$ decade. In this study appendicular lump (61.53\%) and appendicular abscess (75\%) were common in males. Ileocaecal tuberculosis was found in 4 females $(66.66 \%)$ and 2 males $(33.33 \%)$. Carcinoma Caecum was found in 8 females $(66.66 \%)$ and 4 males $(33.33 \%)$. Ileopsoas abscess was found in 4 males $(66.66 \%)$ and 2 females $(33.33 \%) .2$ patients of Intussusception were male. In this study of 86 cases, 60 patients $(69.76 \%)$ were related to appendicular pathology either in the form of appendicular lump $(60.46 \%)$ or appendicular abscess (9.30\%). 12 patients $(13.95 \%)$ suffered from carcinoma caecum, 06 patients $(6.97 \%)$ were diagnosed with Ileo-caecal tuberculosis and Ileo-psoas abscess each and 02 patients $(2.32 \%)$ presented with Intussusception.

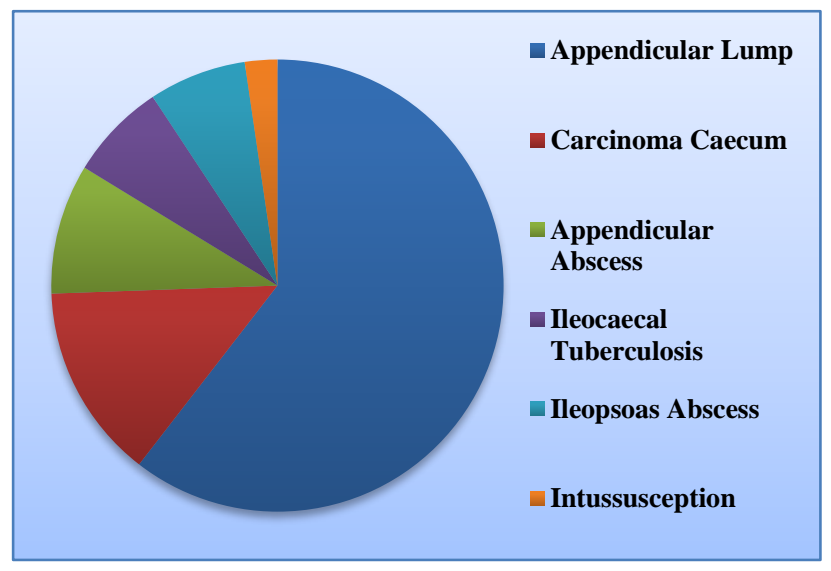

Figure 1: Incidence of various pathologies. 
Pain in abdomen was the main presenting symptom of the study group, the only difference was there in the duration of symptom. In 52 patients of Appendicular lump, 38 patients $(73.07 \%)$ presented with pain in abdomen within a duration of 1 to 7 days, followed by 14 patients $(26.92 \%)$ who gave history of pain in abdomen of duration between 8 to 30 days. All the 08 patients (100\%) of appendicular abscess presented with a pain in abdomen with a duration of 1 to 7 days.04 patients $(66.66 \%)$ of Ileocaecal tuberculosis presented with a complaints of pain in abdomen for a duration of 3 to 6 months and 02 patients with duration more than 6 months. 6 patients (50\%) of Carcinoma Caecum gave history of pain in abdomen over a period of 3 to 6 months, followed by 06 patients $(50 \%)$ over a period of more than 6 months, 02 patients $(16.66 \%)$ over a period of 8 to 30 days. 04 patients $(66.66 \%)$ of Ileopsoas abscess gave history of pain in abdomen for 8- 30 days and 02 patients $(33.33 \%$ ) for a period of 1 to 3 months. 2 patients of Intussusception presented with history of abdominal pain over a period of 1 to 7 days. In present study, only 08 patients $(09.30 \%)$ patients gave history of mass in abdomen, of which 04 patients $(04.65 \%)$ were of Carcinoma Caecum, 02 patients $(33.33 \%)$ was of Ileopsoas abscess, 02 patients $(03.84 \%)$ was of appendicular lump. In present study, 72 patients $(83.72 \%)$ were managed surgically, 14 patients (16.28\%) underwent conservative management. All patients with appendicular lump or abscess were treated surgically either by early appendectomy in patients who were not responding to conservative treatment in the same admission or by interval appendectomy after 6 weeks following completion of Oschner-sherren regimen. None of the patient of ileocaecal tuberculosis presented with features of obstruction, hence continued with ATT without surgical intervention.08 patients of Ca Caecum who were not subjected for surgical intervention as they had advanced disease and their general condition was poor hence put on chemotherapy as palliative therapy.

Table 1: Distribution of mode of treatment.

\begin{tabular}{|llll|}
\hline Diagnosis & $\begin{array}{l}\text { No. of } \\
\text { cases }\end{array}$ & $\begin{array}{l}\text { Conservative } \\
\text { treatment }\end{array}$ & $\begin{array}{l}\text { Surgical } \\
\text { treatment }\end{array}$ \\
\hline $\begin{array}{l}\text { Appendicular } \\
\text { lump }\end{array}$ & 52 & 00 & 52 \\
\hline $\begin{array}{l}\text { Appendicular } \\
\text { abscess }\end{array}$ & 08 & 00 & 08 \\
\hline $\begin{array}{l}\text { Ileocaecal } \\
\text { tuberculosis }\end{array}$ & 06 & 06 & 00 \\
\hline Ca caecum & 12 & 08 & 04 \\
\hline $\begin{array}{l}\text { Ileopsoas } \\
\text { abscess }\end{array}$ & 06 & 00 & 06 \\
\hline Intussusception & 02 & 00 & 02 \\
\hline Total & 86 & 14 & 72 \\
\hline
\end{tabular}

In present study, total of 72 patients underwent surgical treatment of which, 28 patients $(38.88 \%)$ undergone interval appendicectomy after Oschner Sherren Regimen, 16 patients $(22.22 \%)$ underwent early appendicectomy,
08 patients $(11.11 \%)$ who did not respond to Oschner Sherren regimen and showed increase in local or systemic signs were posted for appendicectomy in the same admission. From 12 patients of carcinoma caecum only 04 patients $(25 \%)$ were posted for Right Hemicolectomy with Ileo transverse Anastomosis, rest 08 patients (75\%) with advanced disease and unfit for surgery were managed with conservative palliative treatment. Drainage of appendicular abscess with appendicectomy in same setting done in all 8 patients (100\%). All 6 patients $(100 \%)$ of ileopsoas abscess were treated with extraperitoneal drainage. Resection-anastomosis was done for 2 cases of intussusception. In this study of 86 patients, 17 patients $(19.76 \%)$ had complications, of which 12 patients $(13.95 \%)$ encountered wound infection, 03 patients $(3.48 \%)$ died of which 02 patients were of appendicular abscess who died on post-operative day 2 because of septicaemia and MOF. 1 patient of carcinoma caecum died on post-operative day 14 because of ARDS and subsequent respiratory failure and 02 patients $(02.32 \%)$ had respiratory tract complication.

\section{DISCUSSION}

Total 86 cases were studied over a period of 4 years and most of our findings were consistent with the studies in the literature.

\section{Appendicular lump}

The most common pathological diagnosis of mass in RIF, was appendicular lump, found in $60.46 \%$ of patients. It was more commonly found in the 3 decade of life, the mean age being $30.88 \pm 17.30$ years; more common in males $(61.53 \%)$ than females $(38.47 \%)$; with a M:F ratio of $1.4: 1$, which is comparable with studies by other authors in the Indian sub-continent. ${ }^{5-7}$ In this study, all patients with appendicular lump were treated surgically. 28 patients $(38.88 \%)$ who were kept on Oschner-sherren regimen, responded well and subsequently underwemt interval appendicectomy, 16 patients $(22.22 \%)$ underwent early appendicectomy, 8 patients $(11.11 \%)$ who did not respond to Oschner-sherren regimen were converted to appendicectomy. Shetty SK et al reported $30 \%$ cases with Oschner-sherren regimen followed by interval appendicectomy after 6 to 8 weeks. ${ }^{7}$ Muhammad Ayub J at et al reported $50 \%$ rate of early appendicectomy in appendicular lump, where 30 patients underwent the procedure out of 60 ; whereas the rate of early appendicectomy in our study was $22.22 \%$; i.e. 16 out of 52 cases. $^{8}$ This difference can be attributed to the small sample size and subjective clinical findings of the two studies. According to Erdog D et al, the choice of management in patients with appendicular mass is conservative followed by elective appendicectomy. ${ }^{9}$ In deciding for immediate appendicectomy, the criteria most important are unresponsive to medical treatment and suspicion of malignancy. Ullah $\mathrm{S}$ et al, concluded that conservative management is effective in the majority of the patients. ${ }^{5}$ 


\section{Appendicular abscess}

The management of appendiceal abscesses is still the topic of debate with many modes of treatment options available for the same. Appendicular abscess accounted for $9.30 \%$ of cases in our study. According to JA Blanco Dominguez et al, $6.49 \%$ cases of RIF mass were of appendicular abscess. ${ }^{10}$ Authors encountered $50 \%$ of the cases of appendicular abscess in the 3rd decade with the mean age at $44.50 \pm 19.68$ years, which is consistent with results of Jeong-Ki K et al where mean age of the patients was 50.8 years. ${ }^{11}$ Hornez E et al stated that USG has enabled the diagnosis of appendiceal abscess with a high rate of accuracy (72.7\%), when the sonographic examiner is a surgeon or an emergency physician, the sensitivity rate is better (98.4\%). ${ }^{12}$ Zarba Meli E et al, showed in their study that preoperative ultrasonography showed an accuracy of $85.7 \%$ in detecting the presence of an abscess. ${ }^{13}$ Drainage of abscess and appendicectomy in the same setting is supported by Zarba Meli E et al, who concluded that even in presence of an appendiceal abscess, appendectomy with abscess drainage is not only a safe operation with a low morbidity rate but also the procedure of choice allowing a significant reduction of hospitalization and health cost. ${ }^{13}$ In present study, authors treated all 8 patients surgically by drainage with appendicectomy with minor morbidity in the form of wound infection post operatively and 2 mortalities because of septicaemia with MODS.

\section{Ileo-caecal tuberculosis}

Ileo-caecal (IC) tuberculosis accounted for $6.97 \%$ cases of RIF mass; which is less than half the incidence reported by Kumar $\mathrm{S}$ et al i. e. $16 \%$ patients of IC tuberculosis presenting as RIF mass in their study. ${ }^{14}$ This difference in values may be attributed to different geographical population being studied. In this study $66.66 \%$ of cases of IC Tuberculosis were in the 6th decade of life, with mean age being $49 \pm 16.52$ years. The mean age of the patients in the study by Kishore $\mathrm{P}$ et al was $39.62 \pm 21.18$ years. ${ }^{15}$ In present study IC tuberculosis was more common in females, with $\mathrm{M}: \mathrm{F}$ ratio being 1:2.while Kishore $\mathrm{P}$ et al reported, $\mathrm{M}: \mathrm{F}$ ratio being $1: 1.1{ }^{15}$ Sharma YR concluded in their study that, strongly suggestive clinical features with positive nonspecific investigation findings are also an indication for antitubercular treatment in all endemic countries like Nepal, Bangladesh and India. ${ }^{16}$ In the present series, all patients were managed conservatively with standard DOTS Category-1 regimen, as no patient had signs of intestinal obstruction which warrants emergency surgical intervention.

\section{Carcinoma caecum}

In the present study carcinoma caecum accounted for $13.95 \%$ of patients, which was comparable with the studies of Creerand $\mathrm{S}$ et al and Bakka $\mathrm{R}$ et al; $10 \%$ and $8 \%$ respectively. ${ }^{17,18}$ Mean age of presentation was
57.16 \pm 16.77 years, which correlates with Bafandeh $\mathrm{Y}$ et al who studied 480 consecutive symptomatic patients in which the mean age of presentation was $42.73 \pm 16.21$ years. ${ }^{19}$ All the 12 patients were subjected to USG and yielded the diagnosis of $\mathrm{Ca}$ Caecum which can be supported by Ares $\mathrm{M}$ et al who concluded that abdominal USG has high sensitivity, specificity, PPV and NPV in the diagnosis of colon cancer. ${ }^{20}$ David $\mathrm{A}$ et al, in his study of 3121 eligible persons conducted colonoscopy of 2885 patients for complete evaluation of colon up to the caecum and concluded that it is the important tool for diagnosis of malignancy in colon in the form of diagnostic and screening procedure for the disease. ${ }^{21}$ In present study all 12 cases were subjected to colonoscopy with confirmatory biopsy results. CECT abdomen was done as a part of staging process to aide in the decisionmaking process of providing curative or palliative treatment. Out of 12 patients of carcinoma caecum only 4 patients $(33.3 \%)$ underwent resection followed by chemotherapy, 8 patients were inoperable due to advanced nature of the disease, so treated with palliative chemotherapy. Most of the patients receiving palliative treatment were lost to follow-up after completion of chemotherapy.

\section{Ileo-psoas abscess}

In this study of 86 patients, we encountered 6 patients $(6.97 \%)$ of Ileo-psoas abscess, which can be correlated with the studies done by Shetty SK et al and Malik AH et al, with incidence of $8 \%$ and $10 \%$ respectively. ${ }^{7,22}$ It was common in 4 thand 5 th decade of life $(66.66 \%)$ with a mean age of $33.33 \pm 15.01$ years. Our study showed male preponderance with a $\mathrm{M}: \mathrm{F}$ ratio of $2: 1,2$ patients (33.33\%) had complaints of a lump which were comparable with Shetty SK et al and Tarhan $\mathrm{H}$ et al. ${ }^{7,23}$ All cases of Ileo-psoas abscess were managed surgically by doing Extra-peritoneal drainage followed by DOTS regimen.

\section{CONCLUSION}

In present study, majority of RIF mass pathology was appendicular lump, with pain in abdomen as the commonest presenting symptom. Detailed history and thorough clinical examination is of great importance to reach correct clinicopathological diagnosis. USG abdomen remains specific non-invasive modality of choice in patients with RIF mass to aid in diagnosis. Conservative management followed by Interval appendicectomy is still the choice of management for appendicular lump to avoid operative morbidity. In cases with short duration of lump; early appendicectomy can be undertaken in the same admission. Interval appendicectomy should be considered essential, as the rate of recurrence of appendicits and lump formation is high after conservative management. It also helps in confirmation of diagnosis as it possible to miss other pathologies like I-C Tuberculosis and malignancy. Abscess drainage and appendicectomy of appendiceal 
abscess in the same admission is a safe choice of treatment, thereby reducing further hospitalization and health cost. I-C tuberculosis presenting as RIF mass with no symptoms of intestinal obstruction can be managed conservatively after cytological or serological diagnosis with DOTS Category-1 regimen. In cases where there is a diagnostic dilemma, with non-specific radiological and serological/cytological findings; anti-tubercular therapy can be started empirically based on strong clinical suspicion as it is an endemic disease in the Indian subcontinent. Cases of Ileo-psoas abscess is better managed by extra-peritoneal drainage with concomitant antitubercular therapy. Majority of cases of carcinoma caecum are presenting to the hospital in advanced nonoperable stage. The need of the hour is a multidisciplinary approach between surgeons, general physicians and community health workers to raise the public awareness regarding symptoms of colonic malignancy and conducting effective screening programmes for timely curative intervention.

\section{Funding: No funding sources}

Conflict of interest: None declared

Ethical approval: The study was approved by the Institutional Ethics Committee

\section{REFERENCES}

1. Bhandari RS, Shrestha M, Shrestha GK, Mishra PR, Singh KP. Abdominal lump: a diagnostic dilemma. JNMA. 2009 Jan-Mar;48(173):75-7.

2. Garg P, Dass BK, Bansal AR, Chitkara N. Comparative evaluation of conservative management versus early surgical intervention in appendicular mass a clinical study. J Indian Med Assoc. 1997;95(6):17980,196

3. Way LW. Appendix. Chapter 29. Current surgical diagnosis and treatment, 11th ed. McGraw Hill Companies North America;2003:670-671.

4. Sahu SP, Shukla HS, Abdominal Tuberculosis. Chapter 17. Text book of tuberculosis, 1st edition, Jaypee Brothers Medical Publishers (Pvt) Ltd., New Delhi;2001:187-197.

5. Ullah S, Khan M, Ahmad S, Mumtaz N. Conservative treatment of appendicular mass without interval appendicectomy: is it justified?. J Postgraduate Med Inst (Peshawar-Pakistan). 2011 Sep 8;21(1).

6. Dnyanmote AS, Sinha N, Chavan S, Sable S. Clinicopathological study of right Iliac Fossa Mass. Webmed Central General Surg. 2014;5(11):wme004766.

7. Shetty SK, Shankar M. A clinical study of right iliac fossa mass. Internet J Surg. 2013;30(4).

8. Jat MA, Memon MR, Arshad S, Bozdar AG, Solangi RA. Study of early surgical intervention in appendicular mass. Gomal J Med Sci. 2012 Jul $1 ; 10(1)$.

9. Erdoğan D, Karaman I, Narc1 A, Karaman A, Çavuşoğlu YH, Aslan MK, Çakmak Ö. Comparison of two methods for the management of appendicular mass in children. Pediatric Surg Int. 2005 Feb 1;21(2):81-3.
10. Dominguez JA, Planchar RM, Rocabert JI, Ortiz PL, Gil AC. Medical and/or surgical treatment of appendicular mass and appendicular abscess in children. Cirugia pediatrica: organo oficial de la Sociedad Espanola de Cirugia Pediatrica. 2008 Jan;21(1):43-5.

11. Kim JK, Ryoo S, Oh HK, Kim JS, Shin R, Choe EK, Jeong SY, Park KJ. Management of appendicitis presenting with abscess or mass. J Korean Soc Coloproctol. 2010 Dec 1;26(6):413-9.

12. Hornez E, Gellie G, Entine F, Ottomani S, Monchal T, Meusnier $\mathrm{F}$ et al. Is there still a benefit to operate appendiceal abscess on board French nuclear submarines?. Military medicine. 2009 Aug $1 ; 174(8): 874-7$.

13. Zarba Meli E, Mazzocchi P, Lepiane P, Dalsasso G, Giacovazzo F, Salvio A et al. The role of surgery in the treatment of appendicular abscesses. Italian J Surg. 1997 May;52(5):577-81.

14. KUMAR S. A clinicopathological study of mass in right iliac fossa-a prospective study (Doctoral dissertation, The Rajiv Gandhi University of Health Sciences). 2013.

15. Kishore P, Chandrsekhar T, Palaian S. Diagnosing abdominal tuberculosis: a retrospective study from Nepal. Internet J Gastroenterol. 2008;6(2):87-9.

16. Sharma YR, Roy PK, Hasan M. Abdominal tuberculosis: a study of 25 cases. Kathmandu Univ Med J. 2004 Apr-Jun;2(2):137-41.

17. Creerand S, Feeley TM, Waldron RP. Colorectal cancer over 30 years at one hospital - no evidence for a shift to the right. Int J Colorect Dis. 1999;6(4):184-7.

18. Bakka R, Reddy G. Management of right iliac fossa mass: our experience. J Surg Transplant Sci. 2005;3(1):1009.

19. Bafandeh Y, Khoshbaten M, Sadat AT, Farhang S. Clinical predictors of colorectal polyps and carcinoma in a low prevalence region: Results of a colonoscopy based study. World J Gastroenterol. 2008 March;14(10):1534-8.

20. Martinez-Ares D, Martin-Granizo Barrenechea I, Souto-Ruzo J, Yanez Lopez J, Pallares Peral A, Vazquez-Iglesias JL. The value of abdominal ultrasound in the diagnosis of colon cancer. Rev Esp Enferm Dig (Madird). 2005 Dec;97(12):877-86.

21. Lieberman DA, Harford WV, Ahnen DJ, Provenzale D, Sontag SJ, Schnell TG et al. One-time screening for colorectal cancer with combined fecal occult-blood testing and examination of the distal colon. New Engld J Med. 2001 Aug 23;345(8):555-60.

22. Malik AA, Wani ML, Wani SN, Parray FQ. Evaluating conservative treatment for acute appendicitis with lump formation. J Emerg Trauma Shock. 2012 Jan;5(1):33.

23. Tarhan H, Çakmak Ö, Türk H, Can E, Un S, Zorlu F. Psoas Abscess: Evaluation of 15 cases and review of the Literature. J Urologic Surg. 2014;1:32-5.

Cite this article as: Ramteke $\mathrm{HB}$, Singh $\mathrm{H}$, Wagh DD, Bhoyar RJ. Clinical study of right iliac fossa mass: experience at a rural hospital. Int Surg J 2018;5:2311-5. 